\title{
CONSUMER PREFERENCES AND SWITCHING BEHAVIOR: AN EXPERIMENTAL TESTING OF STATUS QUO EFFECTS IN THE ELECTRICITY MARKET
}

\author{
FABIAN GRABICKI \& ROLAND MENGES \\ Department of Macroeconomics, Clausthal University of Technology, Germany
}

\begin{abstract}
For a long time, consumer research has been investigated the causes of the switching behaviour of consumers in the liberalized electricity market. More recent research in decision theory suggests that consumers non-switching is based on the so-called status quo bias. The status quo bias reflects the tendency to over-proportionally stick to the current state. In an economic decision experiment, the influence of the status quo bias is empirically tested. Using a choice-based conjoint analysis, consumers are offered different variations of electricity contracts. The experimental investigation was conducted in August 2016 in the US state of California. 584 participants in total were assigned randomly in a control and an experimental group to a modified choice-based conjoint analysis. In each of the 15 conducted choice tasks, the participants had to choose an electricity contract. The difference between the control and the experimental group was only that one of the five electricity contracts in each choice task was preselected as a status quo option. The results show significant differences between the control and the experimental group in terms of part-worth utilities for attribute levels and relative importance of attributes. Contrary to the expectations of the rational choice model, the framing of the choice task with and without the preselection of a status quo option significantly influences the decision behaviour of the participants. These results raise doubts as to whether competitive markets driven by individual preferences are a good tool to reward long-term infrastructure and climate policy in the electricity market instead of political measures driven by collective choice. It seems that consumer preferences for preventing climate change are susceptible to framing effects.
\end{abstract}

Keywords: experimental economics, consumer preferences, default, behavioural economics, sustainability, choice-based conjoint analysis, status quo bias.

\section{INTRODUCTION}

In a liberalized electricity market consumers nowadays have the opportunity to opt for any electricity contract. Although a bulk of the population in many surveys expresses a change from their current electricity contract to a new electricity contract, the actual exchange rates remain below expectations [1]. Decision theory, economics and psychology can make a decisive contribution at this point. Here the non-switching can be explained by means of the so-called status quo bias [2]. In general, individuals choose the alternative that maximises their utility if they are confronted with different alternatives, e.g. two electricity contracts. However, if one of the alternatives is highlighted as a status quo, e.g. verbal in text or preselected, previous decision-making experiments demonstrate that individuals stick overproportionally to the status quo. In the studies to date on consumer preferences and switching behaviour, the status quo bias which may influence the behaviour of consumers in reality is not considered methodologically. The central question of this investigation is whether, in repeated electricity contract decisions, the exogenous setting of a specific contract as a status quo leads to a significantly more frequent choice in the survey than in survey situations that do not require such a determination. 


\section{METHOD}

In order to be able to integrate a status quo into the examination design, a modified choicebased conjoint analysis was developed. The modified choice-based conjoint analysis is based on the new approach to consumer theory according to Lancaster [3] and the concept of random utility according to McFadden [4], which serves as a widespread framework for the elicitation of consumer preferences. For simplification, it has been assumed that consumers' utility for electricity contracts is influenced by the attributes "additional costs per month", "electricity mix" and "place of production" (Table. 1) [5].

Consumers give insights into their preferences by choosing one of five electricity contracts with varying attribute combinations in 15 separate choice tasks. The goal of the choice-based conjoint analysis is to make use of the repeated selections between the different electricity contracts within the 15 choice tasks and estimate the part-worth utilities of the attribute levels and the resulting relative importance of the attributes. For this purpose, a multiattribute utility model is used.

\section{EXPERIMENTAL DESIGN AND HYPOTHESIS}

To analyse the status quo bias in the choice of the electricity contracts the participants in the experimental study were divided into a control group and an experimental group. In the experimental group, one of the five electricity contracts was preselected in each of the 15 separate choice tasks. The preselection was defined trough a lexicographical decision rule and was consistently either the most expensive, the most renewable or the most local electricity contract. For the sake of clarity, only the results are shown for the case where the status quo is he most renewable. In the control group, no preselection took place and the participants were able to make an unbiased decision between the different electricity contracts. The following illustration (Fig. 1) outlines the first of the 15 choice tasks for the control and the experimental group. Apart from this little exogenous set default for one of the electricity contracts in each choice task, both experimental studies were exactly the same. This means that the participants were confronted with the same questions, choice options and restrictions. According to the rational choice model in general and the axiom of invariance, the framing of the decision situation should not alter the individual's decision behaviour at all.

Table 1: Attributes and levels.

\begin{tabular}{|l|c|c|c|c|c|}
\hline Attributes & \multicolumn{5}{|c|}{ Levels } \\
\hline $\begin{array}{l}\text { Additional costs } \\
\text { per month }\end{array}$ & $\begin{array}{c}\$ 0 \\
\text { USD }\end{array}$ & $\begin{array}{c}\$ 3 \\
\text { USD }\end{array}$ & $\begin{array}{c}\$ 6 \\
\text { USD }\end{array}$ & $\begin{array}{c}\$ 9 \\
\text { USD }\end{array}$ & $\begin{array}{c}\$ 12 \\
\text { USD }\end{array}$ \\
\hline $\begin{array}{l}\text { Electricity } \\
\text { mix }\end{array}$ & $\begin{array}{c}0 \% \\
\text { renewable }\end{array}$ & $\begin{array}{c}25 \% \\
\text { renewable }\end{array}$ & $\begin{array}{c}50 \% \\
\text { renewable }\end{array}$ & $\begin{array}{c}75 \% \\
\text { renewable }\end{array}$ & $\begin{array}{c}100 \% \\
\text { renewable }\end{array}$ \\
\hline $\begin{array}{l}\text { Place of } \\
\text { production }\end{array}$ & $\begin{array}{c}0 \% \\
\text { local }\end{array}$ & $\begin{array}{c}25 \% \\
\text { local }\end{array}$ & $\begin{array}{c}50 \% \\
\text { local }\end{array}$ & $\begin{array}{c}75 \% \\
\text { local }\end{array}$ & $\begin{array}{c}100 \% \\
\text { local }\end{array}$ \\
\hline
\end{tabular}




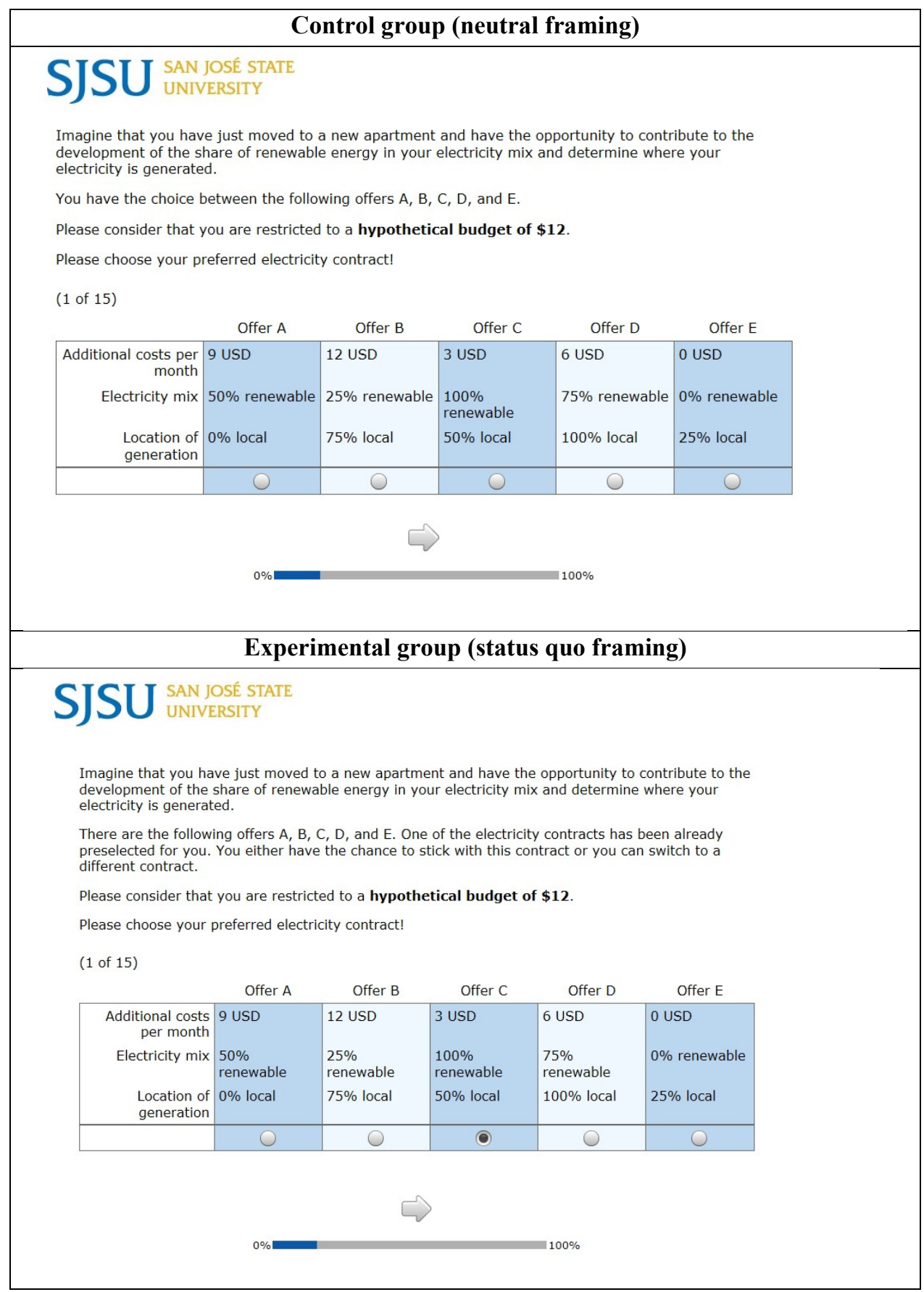

Figure 1: Different framing scenarios between the control and experimental group. 
Based on the presented lexicographical decision rule for the determination of the status quo alternative the following null hypothesis can be formulated:

- Null hypothesis 1: The part-worth utilities of the different attribute levels do not differ between the status quo framing, in which the most renewable electricity contract is preselected in each choice task, and the neutral framing, in which no electricity contract is preselected.

- Null hypothesis 2: The relative importance of the attribute "electricity mix" which is emphasized by the level of the most renewable electricity contract in the status quo framing, does not change in comparison to the neutral framing.

\section{RESULTS}

To investigate the first null hypothesis the part-worth utilities of the control and the experimental group are compared. The following table (Table. 2) shows the medians of the estimated part-worth utilities, the p-values and the effect sizes based on the choices of the two-respective choice-based conjoint analysis. The individual part-worth utilities were estimated using the Hierarchical Bayes Choice-Based Conjoint Model.

Using the nonparametric Mann-Whitney-U-Test significant differences in the part-worth utilities for the attribute levels between the control and the experimental group can be determined. The null hypothesis 1 that states that the part-worth utilities of the attribute levels between the control and the experimental group do not differ, can be denied.

Table 2: Medians of part-worth utilities, p-values and effect sizes.

\begin{tabular}{|c|c|c|c|c|c|}
\hline \multirow[b]{2}{*}{ Attributes } & \multirow[b]{2}{*}{ Attribute levels } & \multicolumn{2}{|c|}{$\begin{array}{c}\text { Median of part-worth } \\
\text { utilities }\end{array}$} & \multicolumn{2}{|c|}{$\begin{array}{l}\text { Mann-Whitney-U- } \\
\text { Test }\end{array}$} \\
\hline & & $\begin{array}{l}\text { Control } \\
\text { group }\end{array}$ & $\begin{array}{l}\text { Experimental } \\
\text { group }\end{array}$ & p-value & $r$ \\
\hline \multirow{5}{*}{ 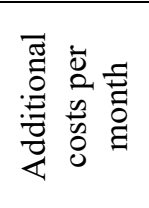 } & \$0 USD & 0.56 & 0.41 & .099 & -0.13 \\
\hline & $\$ 3$ USD & 0.81 & 0.63 & .163 & -0.11 \\
\hline & \$6 USD & 0.34 & 0.32 & .751 & -0.03 \\
\hline & \$9 USD & -0.17 & 0.01 & .173 & -0.11 \\
\hline & $\$ 12$ USD & -2.01 & -1.06 & $.019^{*}$ & -0.19 \\
\hline \multirow{5}{*}{ 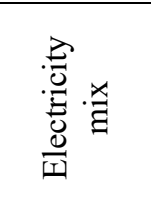 } & $0 \%$ renewable & -2.81 & -4.67 & $.000 * * *$ & -0.44 \\
\hline & $25 \%$ renewable & -0.91 & -2.68 & $.000 * * *$ & -0.37 \\
\hline & $50 \%$ renewable & 0.45 & -0.42 & $.034 *$ & -0.17 \\
\hline & $75 \%$ renewable & 1.28 & 1.49 & .183 & -0.11 \\
\hline & $100 \%$ renewable & 1.05 & 4.30 & $.000 * * *$ & -0.51 \\
\hline \multirow{5}{*}{ 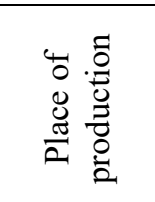 } & $0 \%$ local & -0.65 & -0.80 & .725 & -0.03 \\
\hline & $25 \%$ local & 0.02 & 0.24 & .275 & -0.09 \\
\hline & $50 \%$ local & 0.47 & 0.06 & $.008^{* *}$ & -0.22 \\
\hline & $75 \%$ local & 0.27 & 0.11 & .292 & -0.09 \\
\hline & $100 \%$ local & 0.20 & 0.26 & .469 & -0.06 \\
\hline
\end{tabular}

Null hypothesis „The part-worth utilities of the different attribute levels do not differ between the status quo framing, in which the most renewable electricity contract is preselected in each choice task, and the neutral framing, in which no electricity contract is preselected" Test of null hypothesis using Mann-Whitney-U-Test (asymptotic significances). $* * * / * * / *:=$ Significant on $0,1 \%-/ 1 \%-/ 5 \%$-level 
Table 3: Medians of relative importance of attributes, $p$-values and effect sizes.

\begin{tabular}{|l|r|r|r|r|}
\hline \multicolumn{1}{|c|}{ Attributes } & \multicolumn{2}{|c|}{ Medians of relative importance } & \multicolumn{2}{c|}{ Mann-Whitney-U-Test } \\
\hline & $\begin{array}{c}\text { Control } \\
\text { group }\end{array}$ & $\begin{array}{c}\text { Experimental } \\
\text { group }\end{array}$ & p-value & \multicolumn{1}{c|}{$\mathrm{r}$} \\
\hline Additional costs per month & 33.34 & 21.86 & $.000 * * *$ & -0.39 \\
\hline Electricity mix & 42.80 & 57.30 & $.000^{* * *}$ & -0.52 \\
\hline Place of production & 24.53 & 18.73 & $.002 * *$ & -0.26 \\
\hline $\begin{array}{l}\text { Null hypothesis ,, The relative importance of the attribute "electricity mix" which is emphasized by the level } \\
\text { of the most renewable electricity contract in the status quo framing, does not change in comparison to the } \\
\text { neutral framing." Test of null hypothesis using Mann-Whitney-U-Test (asymptotic significances). ***/**/*:= } \\
\text { Significant on 0,1\%-/1\%-/5\%-level }\end{array}$ \\
\hline
\end{tabular}

For an in-depth analysis of the found differences between the part-worth utilities, the relative importance of the attributes is calculated from the received part-worth utilities. Relative importance of the attributes reflects its contribution to the utility of the alternative and is calculated by constructing a ratio with the numerator equalling the difference of the highest value for the levels of a particular attribute and the lowest value for the levels of that same attribute used in the choice-based conjoint analysis study [6]. The denominator of the ratio is the sum of the values obtained in the numerator for all the attributes, which normalizes the scores to sum to 100 percent. Using the relative importance of the attributes increases the statistical power of the previously detected differences. Looking at the relative importance of the attributes, it can be noted that these differ significantly as well (Table. 3). For the specific case that the status quo contract is the most renewable electricity contract in each of the 15 choice tasks, the relative importance of the attribute "electricity mix" increases from 42.80 to $57.30(\mathrm{p}<.000)$.

At the same time, relative importance of the attribute "additional costs per month" falls from 33.34 to $21.68(\mathrm{p}<.000)$ and relative importance of the attribute "place of production" falls from 24.53 to $18.73(<.002)$. Hypothesis 2 that states the relative importance of the attribute "electricity mix" which is emphasized by the level of the most renewable electricity contract in the status quo framing, does not change in comparison to the neutral framing, can be denied.

\section{CONCLUSIONS}

The investigation of the status quo bias in the context of switching behaviour and the elicitation of consumer preferences in the electricity market are of relevance for the question whether political projects such as enhancing the sustainability of the electricity system can be promoted by voluntary market activities. Contrary to the assumptions of the rational choice model, the utility maximising selection of alternatives in multiple decision-making seems not to be independent of the type of framing. The invariance thesis implies that independent of the type of framing the resulting decision should remain the same. Here, a deviation of the decision-making behaviour could be empirically determined. The results of our experiment show that the monetary and environmental valuation of the attributes are significantly affected by the procedure individuals had to follow when they were offered the opportunity to make a choice. Of course, the empirical findings of this status quo bias are not the only possible explanations for missing or unexpected market activities. There are potential more biases of consumers when they have to make rational decisions in proenvironmental situations such as loss and risk aversion, satisficing and sunk costs [7]. For the liberalized electricity market, these result can be of relevance. The determination of a 
status quo bias in an electricity contract decision scenario can be one reason for the low switching behaviour among electricity customers. Should this be the case, consideration may be given as to how this may be approached, e.g. by defaults or nudges in the sense of libertarian paternalism. This form of governmental coordination overcomes the limitations of human rationality and promotes socially desirable developments. At the same time, the freedom of the consumers or citizens of a state should not be restricted [8]. The results also contribute to the elicitation of consumer preferences using methods such as the choice-based conjoint analysis. If significant deviations in the decision-making behaviour and the resulting consumer preferences arise as a result of a small change in the design of the experimental set-up during repeated choice tasks, this should be taken into account in future survey situations and in the interpretation of these results. Decision rules such as a complete compensatory processing of all attributes and alternatives that is a mandatory condition for all kinds of conjoint analysis are violated if consumers follow a non-compensatory decision rule. Practioners and policymakers should be encouraged to consider this persistent cognitive bias when deciding on how to best transform consumer's intention to consumers' action.

\section{REFERENCES}

[1] Giulietti, M., Otero, J. \& Waterson, M., Pricing behavior under competition in the UK electricity supply industry. Oxford Economic Papers, 62, pp. 468-503, 2010.

[2] Samuelson, W. \& Zeckhauser, R., Status quo bias in decision making. Journal of Risk and Uncertainty, 1(1), pp. 7-59, 1989.

[3] Lancaster, K., A new approach to consumer theory. Journal of Political Economy, 74(2), pp. 132-157, 1966.

[4] McFadden, D. \& Train, K., Mixed MNL models for discrete response. Journal of Applied Econometrics, 15(5), pp. 447-470, 2000.

[5] Green, P.E. \& Srinivasan, V., Conjoint Analysis in Marketing: New Developments with Implications for Research and Practice. Journal of Marketing, 54(4), pp. 3-19, 1990.

[6] Kaenzig, J., Heinzle, S. \& Wüstenhagen, R., Whatever the customer wants, the customer gets? Exploring the gap between consumer preferences and default electricity products in Germany. Energy Policy, 53, pp. 311-322, 2013.

[7] Frederiks, E., Stenner, K. \& Hobman, E., Household energy use: Applying behavioral economics to understand consumer decision-making and behavior. Renewable and Sustainable Energy Reviews, 41, pp. 1385-1394, 2015.

[8] Thaler, R. \& Sunstein, C., Libertarian Paternalism. American Economic Review, 93(2), pp. $175-179,2003$. 